\title{
NOUVELLE
}

\section{Lutte d'influence membranaire pour inhiber ou activer le lymphocyte}

\author{
Armand Bensussan
}

Inserm U841, Université Paris XII,

Faculté de Médecine de Créteil,

8, rue du Général Sarrail, 94010 Créteil, France.

armand.bensussan@inserm.fr
> L'activation des lymphocytes T consécutive à l'engagement du TCR ( $T$ cell receptor) est sous le contrôle de co-récepteurs, dont les ligands respectifs sont multiples, et qui interviennent pour modifier qualitativement et quantitativement la réponse cellulaire. On connaissait les récepteurs membranaires CTLA-4, BTLA ( $B$ and $T$ lymphocyte attenuator) et PD-l comme atténuateurs de l'activation des lymphocytes T. II faut à présent ajouter à cette liste le récepteur CD160 qui est ancré à la surface cellulaire par une liaison phosphatidylinositol-glycane [1]. CD160 a été initialement décrit à la surface des lymphocytes NK (natural killer) cytotoxiques et d'une sous-population de lymphocytes $\mathrm{T} \mathrm{CD8}^{+}$et de lymphocytes TCR $\gamma \delta$ [2]. Par la suite, il a été montré que CD160 liait les molécules du CMH de classe I avec une faible affinité, son engagement ayant pour conséquence d'induire l'activation des lymphocytes NK [3]. Les résultats de l'équipe de G.J. Freeman, publiés dans la revue Nature Immunology [4], révèlent qu'après engagement à l'aide d'un anticorps monoclonal spécifique, le récepteur $C D 160$, bien que très faiblement exprimé à la surface des lymphocytes $C D 4^{+}$activés, est capable d'inhiber totalement l'activation lymphocytaire induite lors du recrutement de CD3 seul ou en association avec CD28. Les auteurs démontrent que CD160, qui se lie aux molécules du CMH de classe I avec une faible affinité, interagit avec une plus grande affinité avec le récepteur HVEM (herpes virus entry mediator). Ce dernier sert de voie d'entrée pour le virus de l'herpès, mais peut aussi interagir avec les protéines BTLA, LIGHT et la lymphotoxine $\alpha$ (Figure 1). Le récepteur CD160, tout comme BTLA, interagit spécifiquement avec le CRDl (cystein rich domain 1) d'HVEM, alors que LIGHT se lie aux CRD2-CRD3 de HVEM. De façon très élégante, en utilisant des molécules chimériques, cette équipe établit la conséquence fonctionnelle de l'ensemble de ces interactions moléculaires au cours de la réponse spécifique d'un lymphocyte $\mathrm{T} C D 4^{+}$mis en présence d'une cellule présentatrice de l'antigène portant HVEM : la résultante est la dominance du co-signal inhibiteur délivré par BTLA et CD160 sur le puissant co-signal activateur dépendant de LIGHT. Néanmoins, plusieurs questions se posent à la lecture de ce travail. Les mécanismes moléculaires du signal inhibiteur consécutif à l'engagement de CD160 sont peu explorés. Notamment, il est important de savoir s'il est différent de celui qui implique le récepteur BTLA. Concernant l'inte-

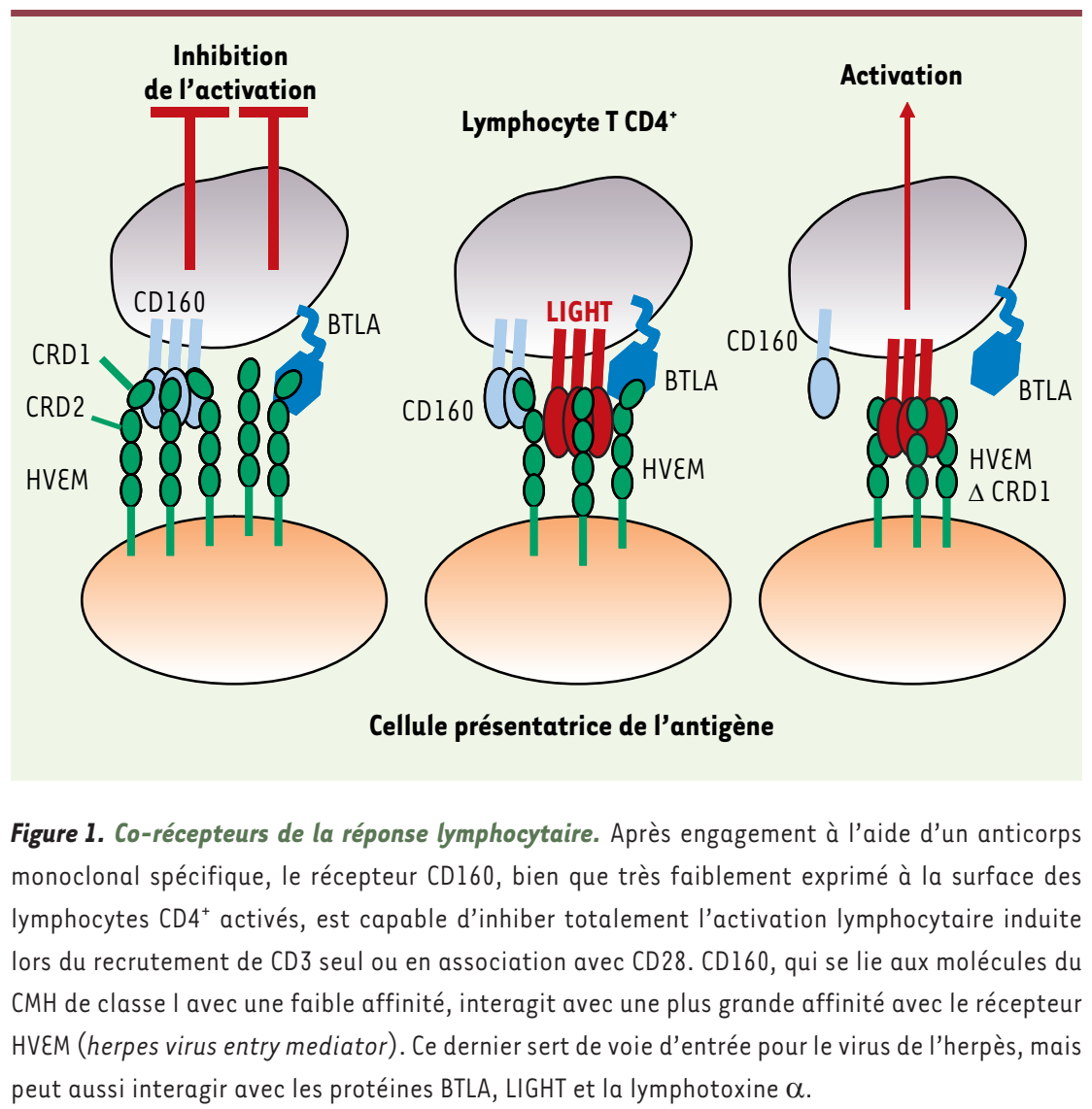


raction de CDI60 avec HVEM, CD160 qui est exprimé sous une forme multimérique à la surface cellulaire va-t-il interagir avec la forme monomérique de HVEM comme le fait BTLA, ou avec la forme trimérique qui est induite lors de son interaction avec LIGHT? Par ailleurs, ces résultats soulèvent le problème du seuil de détection de récepteurs fonctionnels à la surface cellulaire en cytométrie en flux. Au dire des auteurs CDI60, bien qu'il ne soit pas détecté en cytométrie en flux, est exprimé à la surface de l'ensemble des lymphocytes T CD $4^{+}$activés et surtout, il est capable de se lier au récepteur HVEM et d'induire une inhibition presque totale de l'activation cellulaire. Enfin, il reste à expliquer comment l'engagement de CDI60 à la surface des lymphocytes NK induit une activation cellulaire [3]. $\diamond$

CD160 binding to HVEM triggers an inhibitory signal to the activated T cell

\section{RéFÉRENCES}

1. Giustiniani J, Marie-Cardine A, Bensussan A. A soluble form of the MHC class I-specific CDI60 receptor is released from human activated NK lymphocytes and inhibits cell-mediated cytotoxicity. J Immunol 2007 ; 178: 1293-300

2. Bensussan A, Gluckman $\varepsilon$, el Marsafy S, et al. By55 monoclonal antibody delineates within human cord blood and bone marrow lymphocytes distinct cell subsets mediating cytotoxic activity. Proc Natl Acad Sci USA $1994 ; 91$ : 9136-40.

3. Le Bouteiller $P$, Barakonyi A, Giustiniani J, et al. Engagement of $\mathrm{CD} 160$ receptor by HLA-C is a triggering mechanism used by circulating natural killer (NK) cells to mediate cytotoxicity. Proc Natl Acad Sci USA 2002 ; 99 : 16963-8.

4. Cai G, Anumanthan A, Brown JA, et al. CDl60 inhibits activation of human $\mathrm{CD}^{+} \mathrm{T}$ cells through interaction with herpesvirus entry mediator. Nat Immunol 2008; $9: 176-85$

\section{$\ll$ Certains I'aiment chaud »}

d'un film-culte de Billy Wilder) qui sert de présentation à une rece tion de Nature sur le rôle de la température dans la détermination du sexe de certaines espèces au cours de l'incubation [1]. La TSD (temperature-dependant sex determination) fut découverte pour la première fois chez un lézard africain à tête rouge (Agama agama), puis chez des sauriens et des tortues [2]. En fait, les sauropsidés dans leur ensemble sont soumis à l'influence de déterminants sexuels, indépendants des gonosomes. Des hypothèses ont été émises sur leur utilité et sur les avantages adaptatifs qu'ils pouvaient procurer. Charnov et Bull, par exemple, avancent l'idée que la variation de la taille induite par le milieu peut intervenir dans la détermination sexuelle adaptative (ESD), dans le sens mâle ou femelle, selon les conditions environnementales et se maintiennent à l'âge adulte [3]. Toutefois, entre l'éclosion et la maturité, l'importance du développement est telle qu'il semblait difficile de démontrer un quelconque

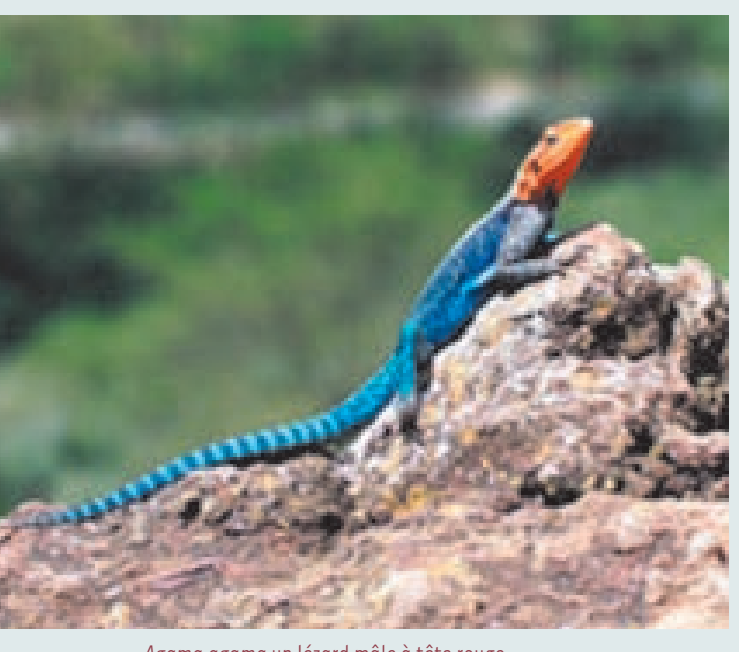

Agama agama un lézard mâle à tête rouge avantage de la TSD et du sex ratio à l'âge adulte. Aucun travail expérimental n'avait permis de le prouver. Mais une récente publication australienne vient enfin d'apporter une preuve de l'avantage adaptatif de la TSD chez un lézard, le jacky dragon ou Amphibolurus muricatus, de la famille des agamidés [4]. L'animal a été soigneusement choisi pour sa vie brève (3-4 ans), car on peut supposer que les effets différentiels de l'incubation retentissent plus nettement chez les animaux à vie brève que chez ceux à vie longue. L'incubation à basse $\left(23^{\circ}-26^{\circ} \mathrm{C}\right)$ et à haute $\left(30^{\circ}-33^{\circ} \mathrm{C}\right)$ température produit des femelles et, entre $27^{\circ}$ et $30^{\circ} \mathrm{C}$, on obtient des mâles et des femelles. Comme il fallait pouvoir observer les deux sexes à différentes températures, les auteurs ont eu recours à une molécule qui interfère avec la biosynthèse des hormones stéroïdiennes, la fadrozole, inhibitrice de l'aromatase. Après incubation aux trois températures 451 : 527-8.

2. Morreale SJ, et al. Science 1982 ; 216: 1245-7.

3. Charnov EL, Bull JJ. Nature 1977 ; 266:828-30.

4. Crews D, Bul JJ. Nature 2008 . 451 : 566-8.

5. Bateson $\mathrm{P}$, et al. Nature 2004 . $430: 419-21$
1. Crews D, Bull JJ. Nature 2008 ; mentionnées ci-dessus, les lézards une fois éclos (une trentaine par groupe) sont élevés séparément et leur développement, leur accouplement et leur production d'œufs sont suivis pendant une période de 3 ans et demi. Un génotypage par microsatellite est effectué pour pouvoir identifier leur descendance et la dénombrer. Le succès reproductif a révélé quelques surprises : les femelles obtenues après incubation à température élevée sont plus grosses et ont un pouvoir reproductif plus important mais aucune différence n'a été observée entre les femelles obtenues aux températures moyenne et basse. Pour les mâles, ceux incubés à température moyenne sont les plus performants. La température d'incubation a des effets multiples sur le comportement, l'anatomie et la physiologie. De plus, quel que soit le sexe gonadique, les taux d'hormones sont d'abord conditionnés par la température d'incubation. Cette étude peut paraître bien ponctuelle, mais il ne faut pas oublier toutefois que les conditions d'incubation et la TSD ont dû préexister à la détermination sexuelle génotypique et que, chez les humains, l'environnement gestationnel a des effets durables tout au long de la vie, influençant des troubles tels que maladies coronariennes, obésité, diabète, et... infertilité [5]. $\diamond$ 